\title{
Efficacy of surgical treatment using microwave coagulo-necrotic therapy for unresectable multiple colorectal liver metastases
}

This article was published in the following Dove Press journal:

OncoTargets and Therapy

25 February 2016

Number of times this article has been viewed

\section{Yoshiyuki Wada \\ Yuko Takami \\ Masaki Tateishi \\ Tomoki Ryu \\ Kazuhiro Mikagi \\ Hideki Saitsu}

Department of Hepato-BiliaryPancreatic Surgery, Clinical Research Institute, National Hospital Organization Kyushu Medical Center, Fukuoka, Japan
Correspondence: Yoshiyuki Wada Department of Hepato-Biliary-Pancreatic Surgery, Clinical Research Institute, National Hospital Organization Kyushu Medical Center, I-8-I Jigyohama,

Chuo-ku, Fukuoka 810-8563, Japan

Tel +8I 928520700

Fax +81 928578802

Email yoshiwada@kyumed.jp
Background: Five or more colorectal liver metastases (CRLM) are considered marginally resectable and cannot be treated solely by hepatic resection $(\mathrm{Hr})$. This study investigated the long-term effectiveness of surgical treatment using microwave coagulo-necrotic therapy (MCN) and/or Hr for marginally resectable or unresectable multiple CRLM.

Methods: This study retrospectively analyzed 82 consecutive CRLM patients with $\geq 5$ CRLM who underwent MCN, Hr, or both, at our institution from 1994 to 2012. Presuming all CRLM were resected curatively, virtual remnant liver volume was calculated using preoperative computed tomography or magnetic resonance imaging. Virtual remnant liver volume $<30 \%$ was defined as unresectable. Patients were divided into marginally resectable (Group Y; n=29) and unresectable (Group N; n=53). Overall and recurrence-free survival were assessed.

Results: Mean maximum tumor diameter and tumor number were 3.1 and $6.0 \mathrm{~cm}$ in Group $Y$ and 3.3 and $11.3 \mathrm{~cm}$ in Group N. Surgical methods included $\mathrm{MCN}(\mathrm{n}=16), \mathrm{MCN}+\mathrm{Hr}(\mathrm{n}=9)$, and $\mathrm{Hr}(\mathrm{n}=4)$ in Group $\mathrm{Y}$, and $\mathrm{MCN}(\mathrm{n}=28)$ and $\mathrm{MCN}+\mathrm{Hr}(\mathrm{n}=25)$ in Group N. One- and 2-year recurrence-free survival rates were $38.0 \%$ and $22.8 \%$ in Group $\mathrm{Y}$, and $18.9 \%$ and $3.8 \%$ in Group $\mathrm{N}(P=0.01)$. However, 1-, 3-, and 5-year overall survival rates of Group N (86.8\%, 44.6\%, and 33.7\%, respectively) were similar to those of Group Y $(82.8 \%, 51.4 \%$, and $33.3 \%$, respectively; $P=$ not significant each).

Conclusion: MCN may improve survival for patients with unresectable multiple CRLM, similar to that in patients with marginally resectable multiple CRLM.

Keywords: colorectal cancer, metastasis, liver, resection, ablation, microwave

\section{Introduction}

Hepatic resection (Hr) is considered the gold standard therapy for colorectal liver metastases (CRLM). Resection of CRLM confined to the liver improves the overall survival of patients and offers the potential of a cure. ${ }^{1}$ However, surgical resection is a viable option in only approximately $20 \%$ of CRLM patients. ${ }^{2}$ According to the National Comprehensive Cancer Network clinical practice guidelines, ${ }^{3} \mathrm{Hr}$ is recommended when curative resection is possible for CRLM, but no strict criteria exist for the number of CRLM. The presence of $\geq 5$ CRLM cannot be treated using hepatectomy alone, and this situation is recognized as unresectable or marginally resectable. Furthermore, the presence of $\geq 5$ CRLM has been reported as an independent prognostic factor for CRLM. ${ }^{1,4}$ European Society for Medical Oncology guidelines define $\geq 5$ CRLM as marginally resectable. ${ }^{5}$ In criteria of the present clinical trial, $\geq 5$ CRLM was recognized as marginally resectable or unresectable. ${ }^{5}$

In the past decade, ablative techniques have emerged as an option for local treatment of liver tumors, including CRLM. ${ }^{6}$ The role of ablation in patients with CRLM is unclear. 
Previous series have suggested that ablation offers improvements in survival compared with chemotherapy alone for unresectable metastases, but is inferior to resection for resectable metastases. ${ }^{7}$ A recent attempt to establish clinical practice guidelines concluded that there was insufficient evidence on which to base guidelines, with wide variability seen in 5-year survival rates $(15 \%-55 \%)$ and a compelling need for more research to determine the efficacy and utility of ablation. ${ }^{8}$

Recently, systemic chemotherapy for colorectal cancer has undergone remarkable development. Response rates have increased to approximately $65 \%$ and median survival of patients treated with palliative chemotherapy has gradually improved to over 30 months. ${ }^{9}$ However, a cure cannot be expected with chemotherapy and only approximately $15 \%$ of patients treated with recent systemic chemotherapy survive 5 years. ${ }^{9}$

Given the challenges in treating patients with initially unresectable multiple CRLM, the use of ablative techniques, either alone or in combination with resection, may increase the number of patients eligible for treatment with potentially curative intent. ${ }^{6}$

The objective of this study was to investigate the efficacy in terms of long-term outcomes in patients with marginally resectable or unresectable CRLM using microwave ablation with or without $\mathrm{Hr}$.

\section{Methods}

Data collected prospectively over a 19-year period (April 1994 to December 2012) for 287 patients who underwent upfront microwave coagulo-necrotic therapy (MCN) and/or Hr for CRLM at our institution were reviewed. The 205 patients who had $\leq 4$ CRLM were excluded from the present study. The 82 patients who had $\geq 5$ CRLM were enrolled in the present retrospective cohort study. The following data were available for curatively operated patients: sex; age; primary tumor site; histologic type; pathologic $\mathrm{T}$ and $\mathrm{N}$ stage according to the current TNM (tumor-node-metastasis) classification; characteristics of liver metastases; operative method; images from preoperative computed tomography (CT) or magnetic resonance imaging (MRI); date of recurrence; date of repeated hepatic surgery; date of re-recurrence; date of re-repeated hepatic surgery; and date of death or last visit.

Intraoperative ultrasonography (IOUS) was routinely performed to confirm the preoperative imaging and diagnosis. Patients with marginally resectable CRLM or with unresectable CRLM amenable to complete treatment with MCN underwent MCN, either alone or in combination with Hr. Patient follow-up included serial measurement of tumor marker levels (carcinoembryonic antigen [CEA] and carbohydrate antigen 19-9 [CA19-9]), CT examination of the chest every 3-6 months, and CT or MRI examination of the abdomen every 3-4 months. All study protocols were approved by the institutional review board at Kyushu Medical Center and performed in compliance with the Declaration of Helsinki. All patients provided written informed consent.

\section{MCN}

All patients underwent open surgical $\mathrm{MCN}$ and/or $\mathrm{Hr}$ performed by experienced hepatobiliary surgeons. Microwaves were generated by a Microtaze generator (Alfresa Pharma, Osaka, Japan) at a frequency of 2,450 MHz. Microwave energy, conducted through an electrode, penetrated a few centimeters into the tissue and caused the tissue to generate heat by changing the polarity of the water molecules. This heat was not emitted externally, but was generated within the target tissue itself. With a single coagulation procedure using a 16-gauge, $150 \mathrm{~mm}$ long needle (MD-16 CBP-1002150; NESCO PERCUPRO-DP, Osaka, Japan) at $65 \mathrm{~W}$ for 1 minute, a coagulo-necrotic area of approximately $1.0 \mathrm{~cm}$ in diameter and $1.5 \mathrm{~cm}$ long was formed around the end of the needle. With a single coagulation using a 21-gauge short needle at 80-85 W for 30 seconds, we formed a columnar necrotic area of approximately $1.0 \mathrm{~cm}$ in diameter and a length that was appropriate to the needle length. We used these two different types of needle to suit the particular conditions of the tumor being treated. The necrotic area formed with a single microwave irradiation was very small. Repeated electrode insertions and irradiations were therefore required to obtain a sufficiently large treated area. At our institution, MCN was essentially performed for tumors $\leq 3 \mathrm{~cm}$ in diameter located as superficial lesions in the liver and for tumors $\leq 2 \mathrm{~cm}$ in diameter located deeper in the liver. ${ }^{10}$ In all cases, IOUS was routinely performed to guide surgical planning. Under IOUS guidance, an antenna was inserted and ablation was performed. MCN treatment was considered complete when a margin of $10 \mathrm{~mm}$ of healthy surrounding parenchyma had also been ablated in continuity with the tumor.

\section{Virtual remnant liver volume}

All patients were retrospectively assessed to calculate virtual remnant liver volume (VRLV) using preoperative contrastenhanced CT on the assumption that all CRLM had been resected. A virtual transection line was designed with a resection margin of $1 \mathrm{~cm}$ for R0. Area of the whole liver and virtual transection area were measured in every 3 to $5 \mathrm{~mm}$ slice from enhanced CT. Volumes of the whole liver and resected liver were calculated as the sum of every measured area, and VRLV ratio was then estimated. CRLM were defined as "marginally resectable" for VRLV ratio $\geq 30 \%$ and "unresectable" for 
VRLV ratio $<30 \%$. Partial hepatectomy was fundamentally considered. However, when tumor was very closely adjacent to a Glisson's capsule or hepatic vein, the virtual transection line/plane was planned to resect these vessels. When nodules of CRLM were clustered in a region, segmentectomy was planned to resect the clustered region.

\section{Statistical analysis}

Groups were compared using the unpaired Student's $t$-test for continuous variables and using Fisher's exact test or the chi-square test for categorical variables. Overall survival was defined as the interval between initial treatment and death, or date of last or most recent follow-up visit. Recurrence-free survival (RFS) was defined as the interval between initial treatment and date of the first treatment for recurrence. Survival curves were calculated using the Kaplan-Meier method and compared with the log-rank test. Values of $P<0.05$ were considered statistically significant. Statistical analyses were performed using JMP version 11.0 software (SAS Institute Inc., Cary, NC, USA).

\section{Results}

\section{Characteristics at baseline}

Table 1 shows a comparison of characteristics between the marginally resectable group (Group Y) and the unresectable group (Group N). Mean maximum diameter of CRLM did not differ significantly between groups. Mean number of CRLM was significantly higher (11.3) in Group $\mathrm{N}$ than in Group Y $(6.0 ; P<0.001)$. Operative procedure in Group Y was $\mathrm{Hr}$ alone for four patients, $\mathrm{MCN}$ alone for nine patients, and $\mathrm{Hr}+\mathrm{MCN}$ for 16 patients. In Group N, Hr alone was not performed, $\mathrm{MCN}$ alone was performed for 25 patients, and $\mathrm{Hr}+\mathrm{MCN}$ for 28 patients $(P=0.01)$.

\section{Overall survival}

Overall survival rate at 1,3 , and 5 years was $82.8 \%, 51.4 \%$, and $33.3 \%$, respectively, in Group $Y$, and $86.8 \%, 44.6 \%$, and $33.7 \%$, respectively, in Group N ( $P=\mathrm{NS}$ ) (Figure 1). Overall survival rates were very similar between groups.

\section{RFS}

RFS at $0.5,1$, and 2 years in Group N $(45.3 \%, 18.9 \%$, and $3.8 \%$, respectively) was inferior to that in Group Y $(51.7 \%$, $37.9 \%$, and $22.8 \%$, respectively; $P=0.01$ each) (Figure 2 ).

\section{Site of recurrence}

When site of recurrence was investigated, almost all patients in both groups experienced hepatic recurrence (Table 2). Although no significant difference was observed, hepatic
Table I Characteristics at baseline

\begin{tabular}{|c|c|c|c|}
\hline Variable & $\frac{\text { Group } Y}{(n=29)}$ & $\frac{\text { Group } N}{(n=53)}$ & $P$-value \\
\hline Age, years & 63.8 & 61.9 & 0.35 \\
\hline \multicolumn{4}{|l|}{ Sex } \\
\hline Male & II & 40 & \multirow[t]{2}{*}{0.20} \\
\hline Female & 18 & 13 & \\
\hline \multicolumn{4}{|l|}{ Timing of CRLM } \\
\hline Synchronous & 15 & 27 & \multirow[t]{2}{*}{0.69} \\
\hline Metachronous & 14 & 26 & \\
\hline Maximum tumor diameter $(\mathrm{cm})$ & 3.1 & 3.3 & 0.55 \\
\hline Number of CRLM & 6.0 & 11.4 & $<0.001$ \\
\hline \multicolumn{4}{|l|}{ Operative method } \\
\hline $\mathrm{Hr}$ & 4 & 0 & \multirow[t]{3}{*}{0.01} \\
\hline $\mathrm{Hr}+\mathrm{MCN}$ & 16 & 28 & \\
\hline $\mathrm{MCN}$ & 9 & 25 & \\
\hline \multicolumn{4}{|l|}{ Tumor marker } \\
\hline CEA & 186.2 & 77.4 & 0.20 \\
\hline CAI9-9 & 191.4 & 101.1 & 0.36 \\
\hline \multicolumn{4}{|l|}{ Site of primary tumor } \\
\hline Right-side colon & 4 & 10 & \multirow[t]{3}{*}{0.19} \\
\hline Left-side colon & 18 & 24 & \\
\hline Rectum & 7 & 19 & \\
\hline \multicolumn{4}{|l|}{ Primary tumor differentiation } \\
\hline Well differentiated & 12 & 22 & \multirow[t]{3}{*}{0.48} \\
\hline Others & 14 & 26 & \\
\hline Unknown & 3 & 5 & \\
\hline \multicolumn{4}{|l|}{ Depth of primary tumor } \\
\hline TI & 0 & 2 & \multirow[t]{5}{*}{0.35} \\
\hline $\mathrm{T} 2$ & 0 & 4 & \\
\hline T3 & 25 & 42 & \\
\hline $\mathrm{T} 4$ & 3 & 2 & \\
\hline Unknown & I & 3 & \\
\hline \multicolumn{4}{|l|}{ Nodal status of primary tumor } \\
\hline Positive & 5 & 18 & \multirow[t]{3}{*}{0.13} \\
\hline Negative & 23 & 31 & \\
\hline Unknown & I & 4 & \\
\hline
\end{tabular}

Notes: Group Y, marginally resectable; Group N, unresectable.

Abbreviations: CRLM, colorectal liver metastases; $\mathrm{Hr}$, hepatic resection; $\mathrm{MCN}$, microwave coagulo-necrotic therapy; CEA, carcinoembryonic antigen; CAI9-9, carbohydrate antigen 19-9.

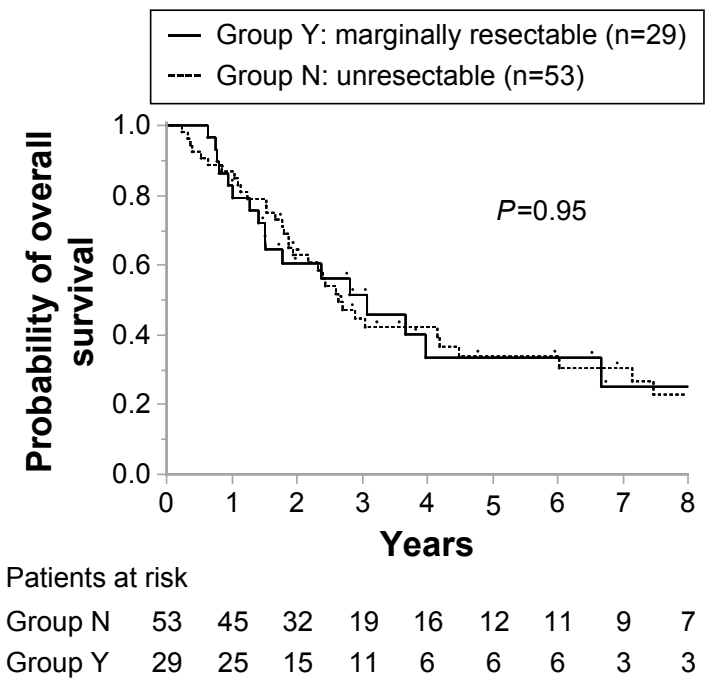

Figure I Overall survival in marginally resectable CRLM patients (Group Y) and unresectable CRLM patients (Group N).

Abbreviation: CRLM, colorectal liver metastases. 


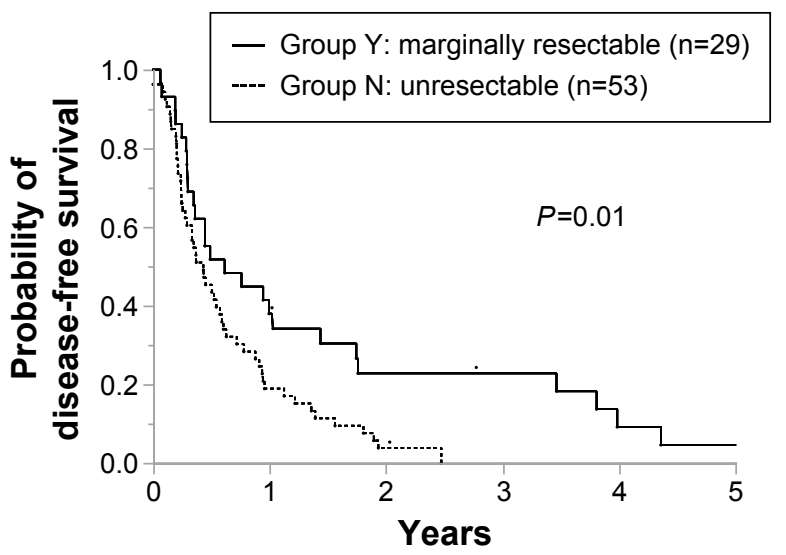

Patients at risk

$\begin{array}{lllllll}\text { Group N } & 29 & 12 & 7 & 0 & 0 & 0 \\ \text { Group Y } & 53 & 11 & 3 & 6 & 3 & 2\end{array}$

Figure 2 Recurrence-free survival in marginally resectable CRLM patients (Group Y) and unresectable CRLM patients (Group N).

Abbreviation: CRLM, colorectal liver metastases.

recurrence rate tended to be higher in Group N (90.4\%) than in Group Y (80.8\%). Extrahepatic recurrence was identified in about half of patients in both groups. Twelve of the 21 patients (57.1\%) and 21 of the 47 patients (44.7\%) with hepatic recurrence underwent repeated hepatic surgery in Group Y and N, respectively.

Table 2 Site of recurrence

\begin{tabular}{|c|c|c|c|}
\hline \multirow[t]{2}{*}{ Variable } & \multirow{2}{*}{$\begin{array}{l}\text { Group } Y \\
(n=29)\end{array}$} & \multirow{2}{*}{$\begin{array}{l}\text { Group N } \\
(n=53)\end{array}$} & \multirow[t]{2}{*}{$P$-value } \\
\hline & & & \\
\hline $\begin{array}{l}\text { Recurrence after initial hepatic } \\
\text { surgery }\end{array}$ & $n=26$ & $n=52$ & \\
\hline \multirow{2}{*}{\multicolumn{4}{|c|}{$\begin{array}{l}\text { Site of recurrence } \\
\text { (\% of recurrence) }\end{array}$}} \\
\hline & & & \\
\hline Remnant liver & $21(80.8)$ & $47(90.4)$ & 0.23 \\
\hline (liver only) & $9(34.6)$ & $24(46.2)$ & 0.33 \\
\hline Lung & $9(34.6)$ & $15(28.8)$ & 0.60 \\
\hline Lymph node & $2(7.7)$ & II (2I.I) & 0.13 \\
\hline Local around primary tumor & $2(7.7)$ & $8(15.4)$ & 0.34 \\
\hline Peritoneum & $4(15.4)$ & $3(5.8)$ & 0.16 \\
\hline Brain & I (3.8) & I (I.9) & 0.61 \\
\hline Bone & $2(7.7)$ & $0(0)$ & 0.04 \\
\hline $\begin{array}{l}\text { Repeat hepatic surgery } \\
\text { (\% of hepatic recurrence) }\end{array}$ & $12(57.1)$ & $21(44.7)$ & 0.34 \\
\hline $\begin{array}{l}\text { Re-recurrence after repeat } \\
\text { hepatic surgery }\end{array}$ & $n=6$ & $n=11$ & \\
\hline \multicolumn{4}{|l|}{ Site of re-recurrence } \\
\hline \multicolumn{4}{|l|}{ (\% of re-recurrence) } \\
\hline Remnant liver & $5(83.3)$ & $8(72.7)$ & 0.62 \\
\hline Lung & $0(0)$ & $\mathrm{I}(9.1)^{\prime}$ & 0.44 \\
\hline Lymph node & I (16.7) & I (9.1) & 0.64 \\
\hline Peritoneum & $0(0)$ & $1(9.1)$ & 0.44 \\
\hline Actual 5-year survivors & 5 & 12 & \\
\hline Repeat surgery episode & 3 & 9 & 0.54 \\
\hline Cancer-free status at 5 years & 3 & 5 & 0.49 \\
\hline
\end{tabular}

Notes: Group Y, marginally resectable; Group N, unresectable.
Furthermore, when site of re-recurrence after repeated hepatic surgery was examined, the composition of re-recurrence differed from that of the initial recurrence. Although extrahepatic recurrence was observed in about half of patients at initial recurrence, only a few patients experienced extrahepatic re-recurrence in both groups. Hepatic recurrence was evident in most patients with re-recurrence in both groups. Moreover, all five patients (100\%) with hepatic re-recurrence underwent re-repeated hepatic surgery in Group Y after repeated hepatic surgery, and six of the eight patients $(75 \%)$ with hepatic rerecurrence in Group N.

\section{Discussion}

The present study investigated the efficacy of our treatment strategy for marginally resectable or unresectable CRLM patients. To divide patients into "marginally resectable" and "unresectable" groups, VRLV was assessed using preoperative CT, and VRLV ratio $<30 \%$ was defined as "unresectable". Results of the present study revealed that aggressive surgical treatment for marginally resectable or unresectable CRLM patients achieved good survival outcomes (5-year survival rate: $33.3 \%$ in marginally resectable group [Group Y]); $33.7 \%$ in Group N.

Although recurrence was observed in most patients in both groups, repeated hepatic surgery could be performed in about half of patients with hepatic recurrence in both groups (57.1\% in Group Y; $44.7 \%$ in Group N). Furthermore, as shown by the site of re-recurrence after repeated hepatic surgery, distant metastases and lymph node metastases decreased compared to initial recurrence. Most re-recurrences after repeated hepatic surgery occurred in the remnant liver, and most patients with hepatic recurrence were able to undergo re-repeated hepatic surgery (100\% in Group Y; $75 \%$ in Group N). Repeated hepatic surgery for hepatic recurrence improved overall survival in both groups. Among the actual 5-year survivors, five patients (41.7\%) in Group $\mathrm{N}$ and three patients (60.0\%) in Group Y had achieved a cancer-free status after repeat hepatic surgery. A previous report ${ }^{11}$ supports the present findings that the incidence of recurrence was high at $87.2 \%$ in the remnant liver, even after curative surgical resection. However, if recurrence was found only in the remnant liver without distant metastasis or lymph node metastasis, repeated resection was possible, and repeated resections were performed in $54.3 \%$ of patients. Re-repeated surgical treatment for frequent recurrences in the remnant liver has been accepted as providing a survival benefit. ${ }^{11,12}$

Prognosis after liver resection has been reported as a 5 -year survival rate of $48 \%-52 \%, 4,11,13$ but those studies 
included only a few patients with $\geq 5$ CRLM. The strongest prognostic factor is considered to be the number of CRLM; the greater the number of CRLM, the lower the survival rate. ${ }^{4}$ However, in the present study, the 5-year survival rate of $33.9 \%$ for all 82 patients with a mean number of 9.3 CRLM was remarkable. Moreover, the present study revealed that the 5-year survival rate of $33.7 \%$ for Group $\mathrm{N}$ with a mean of 11.3 CRLM was similar to that of $33.3 \%$ for Group Y with a mean of 6.0 CRLM.

The efficacy of ablation for CRLM had been well reported, but most reports have examined radiofrequency ablation (RFA), ${ }^{7}$ with only a few large series involving microwave ablation for CRLM. ${ }^{6,14,15}$ However, in theory, microwave ablation shows some advantages over RFA. ${ }^{15,16}$ Faster ablation times, larger ablation zones, higher intratumoral temperature, and more complete coagulative necrosis have been observed with microwave ablation. ${ }^{16,17}$ Microwave ablation is associated with lower local recurrence rates than RFA $^{18}$ and less dependence on the heat-sink effect of vascular structures in proximity to the lesion than RFA. ${ }^{16}$ In addition, we have developed a unique technique for microwave ablation called "MCN", with excellent outcomes based on abundant experience with over 700 hepatocellular carcinoma patients. ${ }^{19}$ The important point with the MCN technique is to prevent scattering of cancer cells around the tumor due to high intratumoral pressure during ablation. In hepatocellular carcinoma, electrode insertion and ablation at the center of the tumor can cause scattering of tumor thrombi into portal veins adjacent to the tumor. To avoid such scattering, MCN starts irradiation from the tissue surrounding the tumor and moves toward the tumor center. The structure of adenocarcinoma with sinusoidal growth differs from that of hepatocellular carcinoma with the formation of portal tumor thrombi, but the theory that high intratumoral pressure from ablation causes scattering of peripheral tumor cells may be applicable to adenocarcinoma. Our MCN technique appears oncologically appropriate.

For unresectable CRLM, two-stage hepatectomy ${ }^{20,21}$ and conversion surgery for unresectable CRLM downstaged by chemotherapy ${ }^{5,13}$ have been reported. However, in the case of two-stage hepatectomy, approximately $25 \%$ of patients do not proceed to the planned second hepatectomy because of disease progression or inadequate remnant hypertrophy. ${ }^{22}$ Furthermore, two laparotomies are needed. In the case of conversion surgery for unresectable CRLM downstaged by chemotherapy, approximately $12.5 \%-20 \%$ of patients proceed to liver resection. ${ }^{5,13}$ Recently, the efficacy of microwave ablation in combination with hepatectomy for unresectable CRLM has been reported. ${ }^{14,23}$ Saxena et $\mathrm{al}^{24}$ analyzed the outcomes of 701 CRLM patients treated with hepatectomy and/or microwave ablation. In 151 patients with $\geq 5$ CRLM, concomitant hepatectomy and microwave ablation were shown to not only achieve comparable survival outcomes to hepatectomy alone, but also effectively expand the criteria for resectability. ${ }^{24}$ Microwave ablation in combination with hepatectomy enables once-only laparotomy to treat multiple CRLM and creates the opportunity for surgical treatment even if the CRLM are classified as "unresectable". Furthermore, microwave ablation enables preservation of not only the remnant liver volume but also important vessels in the liver. Preserving the remnant liver volume and important vessels allows repeated hepatic surgery to be performed when recurrences arise. ${ }^{11}$

Although systemic chemotherapy for patients with CRLM has improved, the incremental benefits have been modest, with overall survival in the absence of surgery of $20 \%-30 \%$ at 3 years. ${ }^{5,25}$ The 3 -year survival rates in patients in Group Y and Group N in the present study were 51.4\% and $44.6 \%$, respectively. Although patients treated with MCN with or without hepatectomy were not compared to those with systemic chemotherapy in the present study, MCN with or without hepatectomy improved survival for marginally resectable or unresectable CRLM patients compared to systemic chemotherapy. ${ }^{26}$

The present study is strengthened by the high quality of the data. All patients were treated at a single institution with extensive experience in caring for patients with CRLM. Data were collected prospectively and follow-up was complete. We chose to focus on overall survival as an indicator of long-term efficacy, because this outcome is objective and most important to patients.

However, several limitations to the present study must be considered. The first limitation concerns a problem with the determination of VRLV. A virtual resection margin of $1 \mathrm{~cm}$ was assumed in this study. While some opinions may consider a smaller resection margin as sufficient, a meta-analysis ${ }^{27}$ reported a negative margin of $\geq 1 \mathrm{~cm}$ confers a survival advantage compared with sub-centimeter negative margins. Other opinions concerning differences in resection planes or resection of vessels adjacent to the tumor are also likely. In the present study, the virtual resection plane took a pessimistic outlook of condition and supposed maximum rather than minimum resection. The second limitation concerns the problem of selecting operative procedures. In general, patients with multiple metastases confined to one region of the liver or with large solitary metastases should undergo resection. Ablation in these settings 
would be inefficient and ineffective. In contrast, ablation may play a role for patients with small metastases deep within the hepatic parenchyma or multiple small metastases scattered throughout the liver. Ablation allows for optimal preservation of parenchyma and extends the reach of potentially curative treatment. The selection seems intuitive which patients should undergo ablation with or without resection.

\section{Conclusion}

The present study revealed the efficacy of surgical treatment using MCN for not only marginally resectable CRLM but also unresectable CRLM. In clinical practice, multiple CRLM are apt to undergo systemic chemotherapy. However, the ultimate goal of treatment for CRLM is prolongation of survival time. Surgical treatment including hepatectomy and MCN should be considered initial treatment for patients with multiple CRLM, even with $\geq 5$ CRLM. For marginally resectable or unresectable CRLM, $\mathrm{MCN}$ in combination with or without hepatectomy may expand the selection criteria for surgery and offer a curative treatment to candidates who would otherwise be offered chemotherapy only. ${ }^{24}$

\section{Disclosure}

This study was presented at the 24th annual conference of Asian Pacific Association for the Study of the Liver (APASL), March 12-15, 2015, Istanbul, Turkey. The authors report no other conflicts of interest in this work.

\section{References}

1. Adam R, De Gramont A, Figueras J, et al. The oncosurgery approach to managing liver metastases from colorectal cancer: a multidisciplinary international consensus. Oncologist. 2012;17(10):1225-1239.

2. Cirocchi R, Trastulli S, Boselli C, et al. Radiofrequency ablation in the treatment of liver metastases from colorectal cancer. Cochrane Database Syst Rev. 2012;6:CD006317.

3. Benson AB 3rd, Venook AP, Bekaii-Saab T, et al. Colon cancer, version 3.2014. J Natl Compr Canc Netw. 2014;12(7):1028-1059.

4. Beppu T, Sakamoto Y, Hasegawa K, et al. A nomogram predicting disease-free survival in patients with colorectal liver metastases treated with hepatic resection: multicenter data collection as a Project Study for Hepatic Surgery of the Japanese Society of Hepato-Biliary-Pancreatic Surgery. J Hepatobiliary Pancreat Sci. 2012;19(1):72-84.

5. Nordlinger B, Van Cutsem E, Gruenberger T, et al. Combination of surgery and chemotherapy and the role of targeted agents in the treatment of patients with colorectal liver metastases: recommendations from an expert panel. Ann Oncol. 2009;20(6):985-992.

6. Karanicolas PJ, Jarnagin WR, Gonen M, et al. Long-term outcomes following tumor ablation for treatment of bilateral colorectal liver metastases. JAMA Surg. 2013;148(7):597-601.

7. Abdalla EK, Vauthey JN, Ellis LM, et al. Recurrence and outcomes following hepatic resection, radiofrequency ablation, and combined resection/ablation for colorectal liver metastases. Ann Surg. 2004;239(6): 818-827.

8. Wong SL, Mangu PB, Choti MA, et al. American Society of Clinical Oncology 2009 clinical evidence review on radiofrequency ablation of hepatic metastases from colorectal cancer. J Clin Oncol. 2010;28(3): 493-508.
9. Heinemann V, von Weikersthal LF, Decker T, et al. FOLFIRI plus cetuximab versus FOLFIRI plus bevacizumab as first-line treatment for patients with metastatic colorectal cancer (FIRE-3): a randomised, open-label, phase 3 trial. Lancet Oncol. 2014;15(10):1065-1075.

10. Wada Y, Takami Y, Tateishi M, Ryu T, Saitsu H. Adaptive criteria of microwave coagulo-necrotic therapy (MCN) for colorectal liver metastases. Journal of Microwave Surgery. 2012;30:103-108.

11. Oba M, Hasegawa K, Matsuyama Y, et al. Discrepancy between recurrence-free survival and overall survival in patients with resectable colorectal liver metastases: a potential surrogate endpoint for time to surgical failure. Ann Surg Oncol. 2014;21(6):1817-1824.

12. de Jong MC, Pulitano C, Ribero D, et al. Rates and patterns of recurrence following curative intent surgery for colorectal liver metastasis: an international multi-institutional analysis of 1669 patients. Ann Surg. 2009;250(3):440-448.

13. Adam R, Delvart V, Pascal G, et al. Rescue surgery for unresectable colorectal liver metastases downstaged by chemotherapy: a model to predict long-term survival. Ann Surg. 2004;240(4):644-657.

14. Martin RC, Scoggins CR, McMasters KM. Safety and efficacy of microwave ablation of hepatic tumors: a prospective review of a 5-year experience. Ann Surg Oncol. 2010;17(1):171-178.

15. Groeschl RT, Pilgrim CH, Hanna EM, et al. Microwave ablation for hepatic malignancies: a multiinstitutional analysis. Ann Surg. 2014; 259(6):1195-1200.

16. Wright AS, Sampson LA, Warner TF, Mahvi DM, Lee FT Jr. Radiofrequency versus microwave ablation in a hepatic porcine model. Radiology. 2005;236(1):132-139.

17. Dupuy DE. Microwave ablation compared with radiofrequency ablation in lung tissue-is microwave not just for popcorn anymore? Radiology. 2009;251(3):617-618.

18. Correa-Gallego C, Fong Y, Gonen M, et al. A retrospective comparison of microwave ablation vs radiofrequency ablation for colorectal cancer hepatic metastases. Ann Surg Oncol. 2014;21(13):4278-4283.

19. Takami Y, Ryu T, Wada Y, Saitsu H. Evaluation of intraoperative microwave coagulo-necrotic therapy (MCN) for hepatocellular carcinoma: a single center experience of 719 consecutive cases. J Hepatobiliary Pancreat Sci. 2013;20(3):332-341.

20. Brouquet A, Abdalla EK, Kopetz S, et al. High survival rate after twostage resection of advanced colorectal liver metastases: response-based selection and complete resection define outcome. J Clin Oncol. 2011; 29(8):1083-1090.

21. Wicherts DA, de Haas RJ, Andreani P, et al. Impact of portal vein embolization on long-term survival of patients with primarily unresectable colorectal liver metastases. Br J Surg. 2010;97(2):240-250.

22. Gamblin TC, Geller DA. Downstaging hepatocellular carcinoma prior to liver transplantation. Liver Transpl. 2005;11(12):1466-1468.

23. Stattner S, Jones RP, Yip VS, et al. Microwave ablation with or without resection for colorectal liver metastases. Eur J Surg Oncol. 2013; 39(8):844-849.

24. Saxena A, Chua TC, Chu FC, Ng KM, Herle P, Morris DL. Impact of treatment modality and number of lesions on recurrence and survival outcomes after treatment of colorectal cancer liver metastases. J Gastrointest Oncol. 2014;5(1):46-56.

25. Falcone A, Ricci S, Brunetti I, et al. Phase III trial of infusional fluorouracil, leucovorin, oxaliplatin, and irinotecan (FOLFOXIRI) compared with infusional fluorouracil, leucovorin, and irinotecan (FOLFIRI) as first-line treatment for metastatic colorectal cancer: the Gruppo Oncologico Nord Ovest. J Clin Oncol. 2007;25(13):1670-1676.

26. Engstrand J, Nilsson H, Jansson A, et al. A multiple microwave ablation strategy in patients with initially unresectable colorectal cancer liver metastases - a safety and feasibility study of a new concept. Eur J Surg Oncol. 2014;40(11):1488-1493.

27. Dhir M, Lyden ER, Wang A, Smith LM, Ullrich F, Are C. Influence of margins on overall survival after hepatic resection for colorectal metastasis: a meta-analysis. Ann Surg. 2011;254(2):234-242. 
OncoTargets and Therapy

\section{Publish your work in this journal}

OncoTargets and Therapy is an international, peer-reviewed, open access journal focusing on the pathological basis of all cancers, potential targets for therapy and treatment protocols employed to improve the management of cancer patients. The journal also focuses on the impact of management programs and new therapeutic agents and protocols on

patient perspectives such as quality of life, adherence and satisfaction. The manuscript management system is completely online and includes a very quick and fair peer-review system, which is all easy to use. Visit http://www.dovepress.com/testimonials.php to read real quotes from published authors.

Submit your manuscript here: http://www.dovepress.com/oncotargets-and-therapy-journal 